\title{
Evolution of ECG Abnormalities in Immune Dysfunction Exacerbation Patients with Chronic Obstructive Pulmonary Disease
}

\author{
Salman Khan ${ }^{1 *}$, Singh Priti' ${ }^{2}$ and Salieva Rana ${ }^{3}$ \\ ${ }^{1}$ Assistant Professor, Department of Pathological Analysis, Knowledge University \\ , Erbil, Iraq \\ ${ }^{2}$ International medical faculty, Osh State University, Osh, Kyrgyzstan \\ ${ }^{3}$ Lecturer, Department of pulmonary, Osh State University, Osh, Kyrgyzstan \\ *Corresponding Author: Salman Khan, Assistant Professor, Medical Microbiology and \\ Immunology, Department of Pathological Analysis, Knowledge University, Erbil, Iraq. \\ DOI: 10.31080 /asmi.2020.03.0568
}

\begin{abstract}
Objective: Chronic obstructive pulmonary disease (COPD) is a major cause of death worldwide. Early identification of the complications, particularly, atherosclerosis, pulmonary hypertension and right ventricular dysfunction can prevent or delay longterm complications. The aim of the present study was to evaluate the prevalence of ECG abnormalities in COPD patients with exacerbation and COPD phenotypes.

Methods: The study population consisted of 364 COPD patients aged 21 to 85 years of either sex. This study was carried out in the department of pulmonology, Osh Interregional United Clinical Hospital, Osh, Kyrgyzstan. Between December 2016 to February 2020. The patients who are diagnosed as having COPD as per GOLD guidelines. ECG was performed with the help of Department of Cardiology.

Results: Highest cases of COPD were found in the age group of 51-65. According to physical examination, spirometry and x-ray out of 364 COPD patients, blue bloaters (BB) 257 (70.60\%), Pink puffers (PP) 41 (11.26\%) and Mixed 66 (18.31\%) were found. Highest BB and mixed were found in 51-65 age group, PP in > 65 age group. Out of 218 male COPD patients, BB 149 (66.97\%), PP 26 (11.93\%) and Mixed 43 (19.72\%) were found. Out of 146 female COPD patients, BB 108 (73.97\%), PP 15 (10.27\%) and Mixed 23 (15.75\%) were found.
\end{abstract}

Out of 364 patients P wave was abnormal in 128 (35.16\%). Tachycardia was observed in 113 (31.04\%), Bradycardia 9 (2.47\%) and 247 (66.86\%) were with normal heart rate. Right heart axis deviation was found in 77 (21.15\%), left 39 (10.17\%), vertical 1 $(0.27 \%)$ and $247(66.86 \%)$ found normal. Vertical heart positioned patients found 87 (23.90\%), horizontal $38(10.44 \%)$ and 239 (65.66\%) found normal. Low voltage was observed in 20 (5.49\%). Incomplete right bundle branch block found in 64 (17.58\%) and complete right bundle branch block found in 02 (0.55\%). ST changes observed in 146 (40.11\%). Tall RV1 was seen in 42 (11.54\%) and Deep SV6 was observed in 169 (46.43\%).

Conclusion: Comparative prevalence was higher in males and 51 - 65 age group at high risk in both sex. Highest BB and mixed found in 51 - 65 age group, PP in > 65 age group. Phenotype BB was more prevalent.ECG abnormalities P-pulmonale, Tachycardia, Right heart axis deviation, Vertical heart position, IRBBB, ST changes Tall RV1 and SV6 was most prevalent. Early diagnosis and management can prevent disease progression of atherosclerosis and hypertension.

Keywords: COPD; Electrocardiography; Blue Bloaters; Pink Puffers; Hypertension; Atherosclerosis

\section{Introduction}

Chronic obstructive pulmonary disease (COPD) is a disease caused by an anomalous activation of the immune system because of lung exposure to irritants affecting normal breathing in a progressive manner $[1,2]$. COPD creates difficulty in proper pulmonary functioning, and this limitation is the main cause for the diagnosis of COPD. Airflow limitation is the slowing of expiratory airflow and it can be measured by Spirometry, which demonstrates a persistently low forced expiratory volume in one second (FEV1) and a low FEV1/forced vital capacity (FVC) ratio even in the presence of treatment $[1,2]$. Other previously existing disease conditions, which can present together or independently, are the usual leading causes of COPD such as chronic bronchitis, small airway disease.

COPD presents a high prevalence and about 200 million peoples all over the world present the disease, posing COPD as the leading cause of morbidity and mortality among chronic diseases. COPD 
is the $4^{\text {th }}$ major cause of death globally and it has been predicted that this disease will become the 3rd one by 2030 [3]. The Global burden of disease project carried out in 2001 identified COPD as the 6th leading cause of death in the developing or underdeveloped world, resulting in $4.9 \%$ of total deaths [4]. A recent study identified COPD as the 4th leading cause of chronic morbidity and mortality and reported that the incidence and prevalence of the disease is continuously on the rise [5]. COPD is the reason of many hospital visits and hospitalizations and frequent cause for work absenteeism. In this regard, a patient with COPD causes personal and healthcare system financial burden. It is necessary to diagnose the disease early and identify patients who are likely to develop complications of pulmonary hypertension, right ventricular hypertrophy and cor pulmonale to prevent long-term complications, extending the patient's life while improving health status.

To the best of our knowledge no studies have been done to estimate the prevalence of ECG variabilities and prevalence of Blue bloaters (Chronic bronchitis) and pink puffers (Severe emphysema) in COPD exacerbation patients in osh region of Kyrgyzstan. Therefore, the aim of the present study was to determine the prevalence of ECG abnormalities in patients with COPD exacerbation attending an in and outpatient clinic of Osh Interregional United Clinical Hospital, Kyrgyzstan. In this study, we aimed to see the prevalence of ECG abnormalities and phenotypes of COPD in different sex and age groups.

\section{Material and Method}

The study population consisted of 364 COPD patients aged 21 to 85 years of either sex. This study was carried out in the department of pulmonology, Osh Interregional United Clinical Hospital, Osh, Kyrgyzstan. Between December 2016 to February 2020.

The diagnosis of chronic obstructive pulmonary disease is made by symptoms in the history and confirmed by physical examination, radiographic examination and lung spirometry for airway obstruction by Spiroanalyzer.

\section{Methodology \\ Inclusion criteria}

The inclusion criteria of the patients were patients who presented with cough, sputum production, dyspnea (wheeze), confirmed absence of sputum acid fast bacillus (AFB), reduced forced expiratory volume (FEV) (below 80\%), FEV < 15\% after inhalation of salbutamol bronchodilator, presence of over inflation, ascites, edema, parasternal heave, jugular venous pressure (JVP) elevation, loud P2, or tricuspid murmur, absence of artery dilatation suggestive of pulmonary arterial hypertension or retrosternal space obliteration evaluated by chest $\mathrm{X}$ ray. Additionally, presence of $\mathrm{p}$ wave morphology in electrocardiogram (ECG), amplitude, 2 ,
$+3+$, avF P amplitude > $9 \mathrm{~mm}, \mathrm{p}$-axis, R-wave $>5 \mathrm{~mm}, \mathrm{r} / \mathrm{s}>50 \%$, existence of right bundle branch block (RBBB).

\section{Exclusion criteria}

Patients with presence of asthma or other chronic restrictive respiratory diseases with need of ventilator, diseases that would potentially stop the study completion, FEV1 $>80 \%$ and reversibility test $>15 \%$, or tuberculosis, were excluded from this study.

After recruitment for the study, a thorough physical examination is done and routine investigations were carried out. The patients were subjected to the following examination. The patients who are diagnosed as having chronic obstructive pulmonary disease as per GOLD guidelines with FEV1/FVC [6] (Table 1).

\begin{tabular}{|c|c|c|c|}
\hline $\begin{array}{c}\text { GOLD } \\
\text { Stage }\end{array}$ & Severity & Symptoms & Spirometry \\
\hline 0 & At Risk & $\begin{array}{c}\text { Chronic cough, spu- } \\
\text { tum production }\end{array}$ & Normal \\
\hline I & Mild & $\begin{array}{c}\text { With or without } \\
\text { Chronic cough or } \\
\text { sputum production }\end{array}$ & FEV1/FVC $<0.70$ \\
FEV1 80\% predicted
\end{tabular}

Table 1: Spirometric Classification of COPD Severity Based on Post-Bronchodilator FEV1 (Based on the guideline of Global initative for Chronic Obstructive Lung Disease (GOLD), 2020).

\section{Electrocardiographic assessment}

A standard 12-lead electrocardiography obtained for each using a portable ECG machine. The following criteria are used to detect right ventricular involvement:

1. P-pulmonale pattern ( $\mathrm{P}$ wave $>2.5 \mathrm{~mm}$ ) in leads II, III, avF;

2. Right axis deviation of QRS complex;

3. $\mathrm{R} / \mathrm{S}$ amplitude ratio in $\mathrm{V} 6$ is less than 1 ;

4. $\mathrm{R} / \mathrm{S}$ amplitude ratio in V1 more than 1 ;

5. Clockwise rotation of the electrical axis;

6. Right bundle branch block; g. S1, Q3 or S1, S2, S3 patterns. 
Thorough echocardiography was performed with the help of Department of Cardiology.

This paper deals with ECG findings among patients of COPD belonging to different age and sex.

\section{Results}

Total 364 COPD patients with and without exacerbations were included in this study $59.89 \%$ male and $40.10 \%$ female (Figure 1).

\section{$\underline{\text { Sex Distribution of cases }}$}

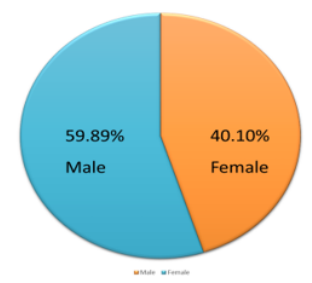

Figure 1

Out of 364 COPD patient 218 were male and 146 females. Highest cases of COPD were found in the age group of 51 - 65 (Table 2).

\begin{tabular}{|c|c|c|c|}
\hline Age group (in years) & Male & Female & Total \\
\hline $21-30$ & 4 & 7 & $11(3.02 \%)$ \\
\hline $31-40$ & 12 & 10 & $22(6.04 \%)$ \\
\hline $41-50$ & 20 & 25 & $45(12.36 \%)$ \\
\hline $51-65$ & 100 & 64 & $164(45.05 \%)$ \\
\hline$>65$ & 82 & 40 & $122(32.97 \%)$ \\
\hline Total & 218 & 146 & 364 \\
\hline
\end{tabular}

Table 2: Gender distribution of COPD patients.

According to physical examination, spirometry and x-ray out of 364 COPD patients, blue bloaters 257 (70.60\%), Pink puffers 41 (11.26\%) and Mixed 66 (18.31\%) were found. Highest BB found in 51-65 age group, PP in $>65$ age group, mixed in $51-65$ age group (Table 3 and Figure 2).

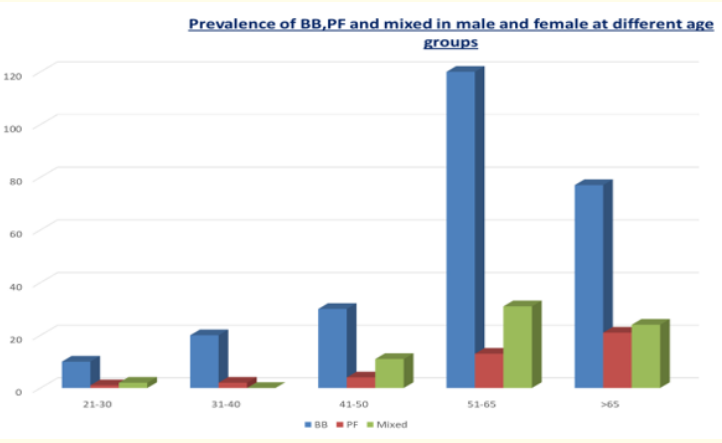

Figure 2

\begin{tabular}{|c|c|c|c|c|}
\hline $\begin{array}{c}\text { Age group } \\
\text { (in years) }\end{array}$ & BB (\%) & PP (\%) & Mixed (\%) & Total (\%) \\
\hline $21-30$ & 10 & 1 & 0 & 11 \\
\hline $31-40$ & 20 & 2 & 0 & 22 \\
\hline $41-50$ & 30 & 4 & 11 & 45 \\
\hline $51-65$ & 120 & 13 & 31 & 164 \\
\hline$>65$ & 77 & 21 & 24 & 122 \\
\hline Total & $257(70.60)$ & $41(11.26)$ & $66(18.31)$ & 364 \\
\hline
\end{tabular}

Table 3: Prevalence of BB, PP and Mixed in male and female at different age group.

Out of 218 male COPD patients, blue bloaters 146 (66.97\%), Pink puffers 26 (11.93\%) and Mixed 43 (19.72\%) were found. Highest BB found in 51 - 65 age group, PP in > 65 age group, mixed in 51 - 65 age group (Table 4).

\begin{tabular}{|c|c|c|c|c|}
\hline $\begin{array}{c}\text { Age group } \\
\text { (in years) }\end{array}$ & BB (\%) & PP (\%) & Mixed (\%) & Total (\%) \\
\hline $21-30$ & 4 & 0 & 0 & 4 \\
\hline $31-40$ & 11 & 1 & 0 & 12 \\
\hline $41-50$ & 12 & 1 & 7 & 20 \\
\hline $51-65$ & 71 & 9 & 20 & 100 \\
\hline$>65$ & 51 & 15 & 16 & 82 \\
\hline Total & $149(66.97)$ & $26(11.93)$ & $43(19.72)$ & 218 \\
\hline
\end{tabular}

Table 4: Prevalence of BB, PP and Mixed in Male at different age group.

Out of 146 female COPD patients, blue bloaters 108 (73.97\%), Pink puffers 15 (10.27\%) and Mixed 23 (15.75\%) were found. Highest BB found in 51 - 65 age group, PP in > 65 age group, mixed in 51 - 65 age group (Table 5).

\begin{tabular}{|c|c|c|c|c|}
\hline $\begin{array}{c}\text { Age group } \\
\text { (in years) }\end{array}$ & BB (\%) & PP (\%) & Mixed (\%) & Total (\%) \\
\hline $21-30$ & 6 & 1 & 0 & 7 \\
\hline $31-40$ & 9 & 1 & 0 & 10 \\
\hline $41-50$ & 18 & 3 & 4 & 25 \\
\hline $51-65$ & 49 & 4 & 11 & 64 \\
\hline$>65$ & 26 & 6 & 8 & 40 \\
\hline Total & $108(73.97)$ & $15(10.27)$ & $23(15.75)$ & 146 \\
\hline
\end{tabular}

Table 5: Prevalence of BB, PP and Mixed in female at different age group.

Out of 364 patients $\mathrm{P}$ wave was abnormal in 128 (35.16\%). Tachycardia was observed in 113 (31.04\%), Bradycardia 9 (2.47\%) and 247 (66.86\%) were with normal heart rate. Right heart axis deviation was found in 77 (21.15\%), left 39 (10.17\%), vertical 1 $(0.27 \%)$ and $247(66.86 \%)$ found normal. Vertical heart positioned patients found 87 (23.90\%), horizontal 38 (10.44\%) and 239 
(65.66\%) found normal. Low voltage was observed in 20 (5.49\%). Incomplete right bundle branch block found in $64(17.58 \%)$ and complete right bundle branch block found in $02(0.55 \%)$. ST changes observed in 146 (40.11\%). Tall RV1 was seen in 42 (11.54\%) and Deep SV6 was observed in 169 (46.43\%) (Table 6).

\begin{tabular}{|c|c|c|c|}
\hline S.N. & ECG & Abnormalities & Prevalence (\%) \\
\hline \multirow{2}{*}{1.} & \multirow{2}{*}{ P- Wave } & Yes & $128(35.16 \%)$ \\
\hline & & No & $236(65.83 \%)$ \\
\hline \multirow{3}{*}{2.} & \multirow{3}{*}{ Heart rate } & Bradycardia $<60$ & $9(2.47 \%)$ \\
\hline & & Normal 60- 100 & $242(66.48 \%)$ \\
\hline & & Tachycardia > 100 & $113(31.04 \%)$ \\
\hline \multirow{4}{*}{3.} & \multirow{4}{*}{ Axis deviation } & Right & 77 (21.15\%) \\
\hline & & Left & 39 (10.17\%) \\
\hline & & Vertical & $01(0.27 \%)$ \\
\hline & & Normal & 247 (66.86\%) \\
\hline \multirow{3}{*}{4.} & \multirow{3}{*}{ Heart position } & Vertical & $87(23.90 \%)$ \\
\hline & & Horizontal & 38 (10.44\%) \\
\hline & & Normal & $239(65.66 \%)$ \\
\hline \multirow{2}{*}{5.} & \multirow{2}{*}{ Low voltage } & Yes & $20(5.49 \%)$ \\
\hline & & No & $244(94.50 \%)$ \\
\hline \multirow{3}{*}{6.} & \multirow{3}{*}{$\begin{array}{l}\text { Bundle Branch } \\
\text { Block }\end{array}$} & IRBBB & $64(17.58 \%)$ \\
\hline & & CRBBB & $02(0.55 \%)$ \\
\hline & & Normal & $298(81.87 \%)$ \\
\hline \multirow{2}{*}{7.} & \multirow{2}{*}{ ST changes } & Yes & $146(40.11 \%)$ \\
\hline & & No & $218(59.89 \%)$ \\
\hline \multirow{2}{*}{8.} & \multirow{2}{*}{ Tall RV1 } & Yes & $42(11.54 \%)$ \\
\hline & & No & $322(88.46 \%)$ \\
\hline \multirow{2}{*}{9.} & \multirow[t]{2}{*}{ Deep SV6 } & Yes & $169(46.43 \%)$ \\
\hline & & No & 195 (53.57\%) \\
\hline
\end{tabular}

Table 6: Prevalence of ECG Abnormalities in COPD patients.

Out of 364 patients Cough, breathlessness and wheezes was observed in $100 \%$ patients. Out of 364 patients rhonchi 75 (20.64\%) fever $22(6.04 \%)$ and weight loss 32 (8.79\%) was found (Table 7).

\begin{tabular}{|c|c|c|c|}
\hline S.N. & Symptoms & & Prevalence (\%) \\
\hline 1. & Cough & Yes & $364(100 \%)$ \\
& & No & $0(0 \%)$ \\
\hline 2. & Breathlessness & Yes & $364(100 \%)$ \\
& & No & $0(0 \%)$ \\
\hline 3. & Wheezes & Yes & $364(100 \%)$ \\
& & No & $0(0 \%)$ \\
\hline 4. & Rhonchi & Yes & $75(20.64 \%)$ \\
& & No & $289(79.40 \%)$ \\
\hline 5. & Fever & Yes & $22(6.04 \%)$ \\
& & No & $342(93.96 \%)$ \\
\hline 6. & Weight- Loss & Yes & $32(8.79 \%)$ \\
& & No & $332(91.21 \%)$ \\
\hline
\end{tabular}

Table 7: Prevalence of Respiratory and other symptoms in COPD patients.

\section{Discussion}

In developing countries, elevated levels of indoor pollution are generated from biomass fuel burning, which has been associated with an increased risk of developing COPD [6]. Many genetic and environmental factors contribute significantly in pathophysiological aspect of COPD. Irritants from cigarette smoke have been reported as the main affecting factor [7]. COPD is triggered when bronchial epithelial cells become damaged because of exposure to air pollution, dust, chemicals, or respiratory infections during childhood, and release of pro-inflammatory mediators to stimulate leukocytes recruitment [6].

When the exposure is chronic in nature, structural and inflammatory cells in the respiratory tract become activated $[8,9]$. For example, cigarette smoke activates pulmonary innate immune defense mechanism altering the epithelial barrier, stimulating clearance in mucosal tissue, and releasing antimicrobial peptides, complement components, and surfactants. The immune response reduces motility of cilia which affects mucus removal and causes tissue damage.

In patients with COPD, the innate immune mechanism is activated when respiratory infections are sensed via pathogen-associated molecular pattern-pattern recognition receptor and/or damage-associated molecular pattern pathways $[10,11]$. The receptors stimulation results in activation of alveolar macrophages, monocytes, mast cells, natural killer cells, dendritic cells, neutrophils, and CD8+ T cells. These are the prime cells involved in the immunological changes of COPD [8,9,12]. On the other side, inhaled irritants can activate pro-inflammatory mediators, such as interleukin (IL)-8 (IL8)/CXCL8, IL-1 $\beta$ and tumor necrosis factor- $\alpha$ (TNF- $\alpha)[13,14]$.

Typically, phagocytes control infections but they also control the associated inflammation in healthy subjects; alveolar macrophages phagocytose infiltrated neutrophils and regulate the extent of inflammation by anti-inflammatory processes $[15,16]$. However, patients with COPD present a reduced self-limitation of inflammation by macrophages which, in addition to the induction of neutrophil survival, cause the airways to become loaded with neutrophils explaining the increase in induced sputum $[17,18]$.

An increase in oxidative stress markers including nitric oxide (NO), hydrogen peroxide, and lipid peroxidation products has been reported in COPD [19-21]. In severe cases, the disturb in oxidative stress causes enhancement of activity and/or expression of enzymes like inducible NO synthase $\left(\mathrm{NOS}_{2}\right.$ ) and neuronal NOS (NOS1), increasing $\mathrm{NO}$ and $\mathrm{H}_{2} \mathrm{O}_{2}$ production in lung [22,23]. Unlike patients with mild asthma, who exhale high levels of NO, COPD patients exhale near normal NO levels but during exacerbations NO levels increase [23-25]. It has been suggested that this NO increase 
might be related to the formation of nitrotyrosine adducts, also increased in COPD [26]. On the other hand, $\mathrm{H}_{2} \mathrm{O}_{2}$ production leads to endothelial dysfunction, atherosclerosis, and hypertension [27,28].

It has been suggested that an autoimmune component might be involved in the pathophysiology of Pulsus paradoxus (PP), since an increase in B-cell production has been observed [19,29]. The presence of circulating antinuclear antibodies (ANA) [30], auto-antibodies against elastin, collagen $\mathrm{V}$ [31-33], anti-decorin antibody, and bronchial epithelial cells with IgG and C3 deposition have been described in PP lung [34,35]. In addition to this, smoking has been associated to an increase in class-switched IgG-memory B cells both in plasma and lung. A recent study indicated that COPD patients present autoantibodies against many different self-antigens that were mainly oxidative stress-modified self-proteins $[19,36]$.

Several studies have demonstrated that the importance of the detection of P pulmonale in the ECG, and have correlated it with COPD severity and indication of life long oxygen therapy. In this regard, previous studies have shown variable $\mathrm{P}$ pulmonale percentages such as Lazović B (14.5\%) [37], Banker H (35\%) [38], Mod JS., et al. (45\%) [39], Nalabothu SK (20\%) [40] and Vineeth A (52.5\%) [41].

In our study, 128/364 patients presented P pulmonale (35.16\%). In another study by Reddy., et al. [42] described other findings like atrial ectopics, ventricular ectopics, incomplete RBBB, complete RBBB, and atrial fibrillation and other arrhythmias, which were observed in more than $50 \%$ of their patients. Less common findings included ST segment depression in lead II, III, aVF, T wave inversion in leads V1-V3, RBBB, S wave in lead I sign, ventricular ectopics, multifocal atrial tachycardia and S-I, S-II, S-III pattern4, which are usually observed in moderate COPD. A study by Sharma., et al. [43] showed that $\mathrm{P}$ pulmonale could be an indicator of severe COPD with only few false positives. The combination of rS pattern in lead V5V6, right axis deviation, clockwise rotation, dominant $\mathrm{R}$ in lead aVR and $\mathrm{P}$ pulmonale were indicative of right ventricular hypertrophy (RVH) in patients lacking classical RVH changes in ECG [39].

In our study, tachycardia was observed in 113 patients (31.04\%), bradycardia in 9 (2.47\%) and 247 (66.86\%) presented normal heart rate. Right axis deviation was found in 77 patients $(21.15 \%)$, left axis deviation in 39 (10.17\%), vertical deviation in $1(0.27 \%)$ and 247 (66.86\%) were found to be normal. Vertical heart positioned patients included 87 cases $(23.90 \%)$, horizontal 38 cases $(10.44 \%)$, and 239 cases (65.66\%) were found normal. Furthermore, low voltage was observed in 20 patients (5.49\%). Incomplete RBBB was found in 64 patients (17.58\%) and complete RBBB was reported in 2 cases $(0.55 \%)$. ST changes were observed in 146 cases $(40.11 \%)$.
Tall RV1 was observed in 42 cases (11.54\%) and Deep SV6 was detected in 169 patients (46.43\%).

In the study conducted by Bunker, vertical heart position was observed in $65 \%$ of the patients [38]. Also, $65 \%$ of patients in this study showed dominant $\mathrm{S}$ wave in V5 and V6 and in our study only $46.43 \%$ showed this sign in ECG. Interestingly, Mod., et al. [39] revealed that electrocardiographic changes in chronic cor pulmonale are due to vertical position of the heart, RVH or both.

\section{Conclusion}

Present study shows high incidence of BB phenotype in 51 - 65 age group COPD patients. Therefore, there is a need for implementing its routine assay in COPD patients, particularly in those patients whose conditions are critical to manage. A proper therapeutic management can prevent the disease progression to atherosclerosis and hypertension, relieve symptoms, improve exercise tolerance and health status, and reduce complications and exacerbations, overall decreasing the disease mortality rate.

\section{Conflict of Interest Statement}

We declare that we have no conflict of interest.

\section{Acknowledgements}

It is our proud privilege to express profound sense of gratitude and sincere thanks to the all the participants and specially Dr Muratov Janibek Kudaybakovich Dean IMF, Dr Sabira Mamatova, IMF, Osh State University, Kyrgyzstan without their guidance and help this study was not possible.

\section{Bibliography}

1. American Thoracic Society. "Chronic bronchitis, asthma and pulmonary emphysema Definitions and classification". American Review of Respiratory Disease 85 (1962): 762-768.

2. American Thoracic Society. "Standards for the diagnosis and care of patients with chronic obstructive pulmonary disease" (1995): 78-79.

3. World Health Organization. "Global Surveillance, Prevention and Control of Chronic Respiratory Diseases: A Comprehensive Approach". Geneva, Switzerland: World Health Organization (2007).

4. Murray CJ., et al. "The Global Burden of Disease 2000 project: aims, methods and data sources" (2001).

5. Devine JF. "Chronic obstructive pulmonary disease: an overview". American Health and Drug Benefits 1 (2008): 34-42.

6. Global Initiative for Chronic Obstructive Lung Disease. "Global Strategy for Diagnosis, Management and Prevention of Chronic Obstructive Pulmonary Disease" (2020). 
7. Postma DS., et al. "Asthma and chronic obstructive pulmonary disease: common genes, common environments?" American Journal of Respiratory and Critical Care Medicine 183 (2011): 1588-1594.

8. Thorley AJ and Tetley TD. "Pulmonary epithelium, cigarette smoke, and chronic obstructive pulmonary disease". International Journal of Chronic Obstructive Pulmonary Disease 2 (2007): 409-428.

9. Brusselle GG., et al. "New insights into the immunology of chronic obstructive pulmonary disease". Lancet 378 (2011): 1015-1026.

10. Lee J., et al. "Cigarette smoking and inflammation: cellular and molecular mechanisms". Journal of Dental Research 91 (2012): 142-149.

11. Rovina N., et al. "Inflammation and immune response in COPD: where do we stand?" Mediators of Inflammation (2013): 413735.

12. Barnes PJ. "Cellular and molecular mechanisms of chronic obstructive pulmonary disease". Clinics in Chest Medicine 35 (2014): 71-86.

13. Karimi K., et al. "Toll-like receptor-4 mediates cigarette smoke-induced cytokine production by human macrophages". Respiratory Research7 (2006): 66.

14. Moodie FM., et al. "Oxidative stress and cigarette smoke alter chromatin remodeling but differentially regulate NF-kappaB activation and proinflammatory cytokine release in alveolar epithelial cells". The FASEB Journal 18.15 (2004): 1897-1899.

15. Silva MT. "Neutrophils and macrophages work in concert as inducers and effectors of adaptive immunity against extracellular and intracellular microbial pathogens". Journal of Leukocyte Biology 87 (2010): 805-813.

16. Silva MT. "Macrophage phagocytosis of neutrophils at inflammatory/ infectious foci: a cooperative mechanism in the control of infection and infectious inflammation". Journal of Leukocyte Biology 89 (2011): 675-683.

17. Kirkham PA., et al. "Macrophage phagocytosis of apoptotic neutrophils is compromised by matrix proteins modified by cigarette smoke and lipid peroxidation products". Biochemical and Biophysical Research Communications 318 (2004): 32-37.

18. Xu Y., et al. "Cigarette smoke (CS) and nicotine delay neutrophil spontaneous death via suppressing production of diphosphoinositol pentakisphosphate". Proceedings of the National Academy of Sciences of the United States of America 110 (2013): 7726-7731.

19. Kirkham PA., et al. "Oxidative stress-induced antibodies to carbonyl-modified protein correlate with severity of chronic obstructive pulmonary disease". American Journal of Respiratory and Critical Care Medicine 184.7 (2011): 796- 802.
20. Ichinose M., et al. "Increase in reactive nitrogen species production in chronic obstructive pulmonary disease airways". American Journal of Respiratory and Critical Care Medicine 162.2-1 (2000): 701-706.

21. Paredi P., et al. "Exhaled ethane, a marker of lipid peroxidation, is elevated in chronic obstructive pulmonary disease". American Journal of Respiratory and Critical Care Medicine 16.2-1 (2000): 369-373.

22. Lim S., et al. "Relationship between exhaled nitric oxide and mucosal eosinophilic inflammation in mild to moderately severe asthma". Thorax 55.3 (2000): 184-188.

23. Maziak W., et al. "Exhaled nitric oxide in chronic obstructive pulmonary disease". American Journal of Respiratory and Critical Care Medicine 157.3.1 (1998): 998- 1002.

24. Sapey E and Stockley RA. "COPD exacerbations. 2: aetiology". Thorax 61.3 (2006): 250-258.

25. Ricciardolo FL., et al. "Nitrosative stress in the bronchial mucosa of severe chronic obstructive pulmonary disease". The Journal of Allergy and Clinical Immunology 116.5 (2005): 1028-1035.

26. Yoshida T and Tuder RM. "Pathobiology of cigarette smoke induced chronic obstructive pulmonary disease". Physiological Reviews 87.3 (2007): 1047-1082.

27. Capettini LS., et al. "Decreased production of neuronal NOSderived hydrogen peroxide contributes to endothelial dysfunction in atherosclerosis". British Journal of Pharmacology 164 (2011): 1738-1748.

28. Silva GC., et al. "Endothelial dysfunction in DOCA-salt-hypertensive mice: role of neuronal nitric oxide synthase-derived hydrogen peroxide". Clinical Science 130 (2016): 895-906.

29. Brusselle GG., et al. "New insights into the immunology of chronic obstructive pulmonary disease". Lancet 378.9795 (2011): 1015-1026.

30. Bonarius HP., et al. "Antinuclear autoantibodies are more prevalent in COPD in association with low body mass index but not with smoking history". Thorax 66.2 (2011): 101-107.

31. Lee SH., et al. "Antielastin autoimmunity in tobacco smoking induced emphysema". Nature Medicine 13.5 (2007): 567-569.

32. Rinaldi M., et al. "Antielastin B-cell and T-cell immunity in patients with chronic obstructive pulmonary disease". Thorax 67.8 (2012): 694-700.

33. Kuo YB., et al. "Identification and clinical association of anticytokeratin 18 autoantibody in COPD". Immunology Letters 128.2 (2010): 131-136.

34. Feghali-Bostwick CA., et al. "Autoantibodies in patients with chronic obstructive pulmonary disease". American Journal of Respiratory and Critical Care Medicine 177.2 (2008): 156-163. 
35. Brandsma CA., et al. "Differential switching to IgG and IgA in active smoking COPD patients and healthy controls". European Respiratory Journal 40.2 (2012): 313-321.

36. Packard TA., et al. "COPD is associated with production of autoantibodies to a broad spectrum of self-antigens, correlative with disease phenotype". Immunology Research 55.1-3 (2013): 48-57.

37. Lazović B., et al. "Analysis of electrocardiogram in chronic obstructive pulmonary disease patients". Medicinski Pregled 66.3-4 (2013): 126-129.

38. Hina Banker and Anita Verma. "Electrocardiographic changes in COPD”. NHL Journal of Medical Sciences 2.2 (2013): 55-58.

39. Jayadev S Mod., et al. " Ecg changes in chronic cor pulmonale”. Indian Journal of Applied Research 4.12 (2014): ISSN-2249555X.

40. Sandeep Krishna Nalabothu and Leela Krishna Kaku. "A study of electrocardiographic changes in chronic obstructive pulmonary disease". Scholars Journal of Applied Medical Sciences 3.1 (2015): 470-472.

41. Alexander V., et al. "Prevalence cardiac comorbidities and its relation to severity staging of chronic obstructive pulmonary disease". International Journal of Contemporary Research and Review 7.17 (2015): 27-33.

42. Sarath Kumar Reddy B., et al. "Electrocardiographic changes in chronic obstructive pulmonary disease". Journal of Evidence Based Medicine and Healthcare 1.3 (2014): 111-117.

43. Ram Abhishek Sharma., et al. "Diagnosis of severity of COPD on the basis of electrocardiogram". Indian Journal of Basic and Applied Medical Research 6.2 (2013): 527-530.

\section{Assets from publication with us}

- Prompt Acknowledgement after receiving the article

- Thorough Double blinded peer review

- Rapid Publication

- Issue of Publication Certificate

- High visibility of your Published work

Website: https://www.actascientific.com/

Submit Article: https://www.actascientific.com/submission.php Email us: editor@actascientific.com

Contact us: +919182824667 